\title{
1 Soil microbial communities in diverse agroecosystems exposed to glyphosate
}

2 Ryan M. Kepler ${ }^{1}$, Dietrich J. Epp Schmidt ${ }^{2}$, Stephanie A. Yarwood ${ }^{2}$, Krishna N. Reddy ${ }^{3}$, Stephen

3 O. Duke ${ }^{4}$, Carl A. Bradley ${ }^{5}$, Martin M. Williams II ${ }^{6}$, Jeffery Buyer ${ }^{1}$, Michel A. Cavigelli ${ }^{1}$, Jude E.

4 Maul $^{1}$

$5 \quad{ }^{1}$ Sustainable Agricultural Systems Laboratory, USDA-ARS

610300 Baltimore Ave, bldg. 001

7 Beltsville, MD 20705

$8 \quad{ }^{2}$ Environmental Science and Technology Department, University of Maryland,

91204 HJ Patterson Hall

10 College Park, MD 20742, USA

$11{ }^{3}$ Crop Production Systems Research Unit, USDA-ARS

12 P.O. Box 350, Stoneville, Mississippi 38776

$13{ }^{4}$ Natural Products Utilization Research Unit, USDA-ARS

14 P.O. Box 1848, University, Mississippi 38677

$15{ }^{5}$ Department of Plant Pathology, University of Kentucky Research and Education Center

16 Princeton, KY 42445

$17{ }^{6}$ Global Change and Photosynthesis Research, USDA-ARS

181102 S. Goodwin Avenue

19 Urbana, Illinois 61801

20 Corresponding author: Jude Maul. Jude.Maul@ARS.USDA.GOV. phone: 301-504-9068

\section{Conflict of interest}

22 The authors declare they have no conflict of interest. 


\section{Abstract}

25 In spite of glyphosate's wide use in agriculture, questions remain about effects of the herbicide on soil microbial communities. Conflicting scientific literature reports divergent results; from no observable effect of glyphosate to the enrichment of common agricultural pathogens such as Fusarium. We conducted a comprehensive field-based study to compare treatments that did and did not receive foliar application of glyphosate spray. The study included two field sites, Maryland and Mississippi; two crops, soybean and corn; four site years, 2013 and 2014; and a variety of organic and conventional farming systems. Using amplicon sequencing, the prokaryotic (16S rRNA) and fungal (ITS) communities were described along with chemical and physical properties of the soil. Sections of corn and soy roots were plated to screen for the presence of plant pathogens. Geography, farming system, and seasonal progression were significant factors determining composition of fungal and bacterial communities. Plots treated with or without glyphosate did not differ in overall microbial community composition after controlling for these factors. No differential effect of glyphosate treatment was found in the relative abundance of organisms such as Fusarium spp. or putative growth-promoting bacteria Pseudomonas spp.

\section{Introduction}

Providing food for the exponentially growing global human population [1] requires agricultural productivity to double by the year 2050 [2]. Thirty six percent of the Earth's potential

44 agricultural land is already under production, and much of the remaining land is considered

45 marginal and susceptible to degradation when put under intensive management [3]. External

46 inputs for nutritional supplementation and pest control are significant production costs and non-

47 point sources of pollution that negatively impact human and environmental health. Thus, to 
Introduction of genetically modified glyphosate-resistant (GR) crops has transformed agroecosystems across the globe by increasing adoption of no-till agriculture where weeds are controlled chemically rather than by tillage [5]. Glyphosate interrupts the shikimate biosynthesis pathway [6], which is responsible for the production of aromatic amino acids and other key components of cell metabolism. The shikimate pathway is found in bacteria, fungi, algae, plants and some protozoans, although not in animals. Glyphosate competitively binds to the enzyme 5enolpyruvylshikimate 3-phosphate synthase (EPSPS) and is known to be lethal to most species of plants and a large proportion fungi. However, some microbes are resistant to glyphosate due

58 to rapid metabolism of glyphosate or to a GR form of EPSPS. Once this biosynthetic pathway is 59 blocked, plants die due to metabolic disruption. Even at sub lethal application rates [7, 8] glyphosate can weaken a plant's hypersensitive response enough that a pathogen is able to infect and kill the plant. In the absence of a pathogen the plant may have a stunted appearance for a few weeks but then recover. application [9]. Glyphosate strongly binds to some soil components, making it rather immobile in most soil types [10]. Its tight binding to soil contributes to its weak phytotoxicity to plants as a soil applied herbicide. The episodic exudation of glyphosate may have indirect effects on the soil microbial community, and these changes may be important to the long term sustainability of agroecosystems, but patterns or changes in the microbial community are difficult to detect in the context of seasonality, changing crop species, and geographic locations.

Concerns have been raised about increased pathogen loads and suppression of

71 beneficial organisms associated with glyphosate use [11,12]. There are two mechanisms by

72 which glyphosate could enrich the soil for plant pathogens: 1) pathogens can attack glyphosate-

73 susceptible weeds that succumb to the herbicide, the dying biomass of which then acts as

74 refugia for subsequent crop infestation (green bridge) or 2) pathogens can gain a "foothold" in a

75 glyphosate-resistant plant due to reduced immune response from alterations in the shikimate 
pathway, resulting in a non-lethal infection that allows the pathogen to propagate. A review of all GR crops by Hammerschmidt [13] determined there is no conclusive evidence that glyphosate increases the susceptibility of GR crops to disease. Another review [14] challenges this conclusion. For example, several studies have observed that GR beets and soybean have increased susceptibility to pathogens when glyphosate is applied at recommended rates [1416]. One study found no effect of glyphosate on disease induction in GR beets until rates exceeded normal field application rates by one order of magnitude [17]. However, other studies with GR crops have found no influence of glyphosate on disease [18], as well as instances of

84 fungicidal activity against plant pathogens, especially rusts (reviewed by Duke [19]).

Two key studies have substantiated the glyphosate-pathogen-enrichment hypothesis,

86 finding over long study periods that glyphosate repeatedly increases the rate of colonization of

87 crops by Fusarium (presumed to be a pathogenic strain), while decreasing the abundance of fluorescent Pseudomonas bacteria (taken as putative beneficial organisms) in the soil $[11,16]$. These studies are often cited as conclusive evidence that long-term use of glyphosate increases the pathogen load and decreases the abundance of growth promoting bacteria in soils. Both studies applied culture-based methodology to quantify these microbial groups, with molecular analysis of the ribosomal internal transcribed spacer region (ITS) for fungi; however, the

93 identification techniques employed were not sufficiently discriminatory to distinguish pathogenic

94 and beneficial genotypes for either group. Studies using culture-free methodology to

95 characterize microbial communities have failed to detect substantial glyphosate effects on

96 pathogen abundance [20, 21]. The key to conclusive determination of glyphosate effect on

97 microbial communities of GR crops is to carefully compare glyphosate sprayed and non-sprayed

98 treatments within an agronomic context. Farming systems, soil factors, crop varieties,

99 glyphosate legacy and application rates can all impact the behavior of glyphosate and its 100 interaction with the crop and soil microbiome [22]. 
We conducted a field-scale study to observe the effects of glyphosate on the soil microbiome and plant health for corn and soybean GR varieties. Specifically, we tested the hypothesis glyphosate changes the composition of the soil microbiome when controlling for differences in soils, seasonal time points, and farming systems. Furthermore, we tested the hypothesis that Fusarium spp. sequence abundance or culturable numbers would increase due to glyphosate treatment. Our study includes six farming systems and a total of 12 site years,

107 representing agricultural practices as implemented on working farms. Our study targeted both

108 naïve soil microbiomes that have not been exposed to glyphosate and those exposed to 109 glyphosate annually. High throughput sequencing was used to generate bacterial and archaeal 110 16S rRNA profiles and fungal ITS profiles.

\section{Materials and Methods}

112 Description of field sites and experimental design: The study was conducted for two years 113 at two United States Department of Agriculture, Agricultural Research Service (USDA-ARS) 114 sites: the Sustainable Agricultural Systems Laboratory, Beltsville, MD and the Crop Production Systems Research Unit, Stoneville, MS.

The Beltsville site is managed as part of a USDA-Long Term Agricultural Research site

117 typical of the mid-Atlantic region and described previously [23, 24]. We conducted the study in 118 two conventional farming systems include one using a chisel plow for primary tillage (CT) and 119 one under no-tillage management (NT). These two systems rely on mineral fertilizers,

120 herbicides, and other pesticides as needed to manage a corn-rye cover crop-soybean-

121 wheat/soybean rotation. One organic farming system is a three-year corn (Zea maize) -rye

122 (Cereale secale) cover crop -soybean (Glycine max) -wheat (Triticum aestivum)/legume (Vicia 123 villosa) rotation (Org3). The second organic farming system is a six-year crop rotation (Org6) in 124 which alfalfa (Medicago sativa), a perennial crop in place for three years of the rotation, 125 replaces the vetch present in Org3. The organic systems rely on legumes, poultry litter and $126 \mathrm{~K}_{2} \mathrm{SO}_{4}$ to supply crop nutrients in accordance to soil test results and local regulations. A 
127 moldboard plow and/or a chisel plow is used for primary tillage in the organic systems. Weed 128 control in the organic systems included use of a rotary hoe and between row cultivation after 129 crops were planted.

In Stoneville the experiment was conducted in two adjacent fields, one with a legacy of glyphosate use, the other with no glyphosate history. The field with a history of glyphosate use had GR soybean and cotton (Gossypium hirsutum) grown in rotation for the last 15 years prior to the experiment. The field without glyphosate history had been maintained for weed biology

134 studies in a cogongrass [Imperata cylindrica (L.) Beauv.] monoculture with no herbicides applied 135 for 12 years prior to the experiment. Field preparation included killing the cogongrass with repeated tillage, planting non-GR soybean and non-GR corn for one season prior to the current field experiment, and flail mowing at maturity.

The experiment was conducted during both the corn and soybean phases of crop rotations at both sites. At each site the following glyphosate treatments were established: a GR cultivar with no glyphosate applied and the same GR cultivar with glyphosate applied at $0.87 \mathrm{~kg}$ $141 \mathrm{ha}^{-1}$ twice at 5 and 7 weeks after planting. Each plot was four rows $(4.6 \mathrm{~m})$ wide and $6.1 \mathrm{~m}$ 142 long. Soybean cultivar USG Allen (GR) was planted at 350,000 seeds ha ${ }^{-1}$ and the corn cultivar 143 DKC 65-17 RR2 (GR) was planted at 30,000 seeds ha-1. In Beltsville the corn or soybean plots 144 are each a phase of the main plot rotation which is farming system (NT-18yr, CT-18yr, Org3145 none or Org6-none) in this experimental design each phase of the rotation is considered a split146 plot of the main plot which is cropping system. At both sites four replicates of each factor and 147 level were established. All plots were hoed by hand periodically throughout the season to keep 148 them weed-free. In October of each year, corn was harvested with an Almaco small plot combine

150 (Almaco, Nevada, IA); grain yield was estimated at 15.5\% moisture from the two center rows of 151 the 6.1 m plots. In 2013 the soybean was harvested with a Almaco small plot combine and in 
2014 the soybean were hand harvested and threshed from $3.05 \mathrm{~m}$ of the two center rows. Dry weights were calculated at $13.5 \%$ moisture.

\section{Soil Baseline Characteristics}

Beltsville soils are Coastal Plain silty loam Ultisols, consisting primarily of Christiana, Keyport, Matapeake and Mattapex soil map units. The soils at the Stoneville site were a silt loam typic Endoqualfs dominated by Dundee soil map units. At planting, soil samples from the top $15-\mathrm{cm}$ depth were collected from each plot by combining soil from six or more cores $(7.5 \mathrm{~cm}$ diameter and $15 \mathrm{~cm}$ depth) sampled in a semi-random pattern in a given plot. Samples were airdried and sieved to $2 \mathrm{~mm}$. The cores were collected on a diagonal line between the second and third crop rows, $3 \mathrm{~m}$ from each end of a given plot. Soil samples were analyzed by the

\section{Rhizosphere Soil and Root Sampling}

At the V3 to V4 crop growth stage (4 to 6 weeks after planting) and one day prior to glyphosate application six plants and root-associated soil were excavated from each plot by

171 removing soil monoliths with $15 \mathrm{~cm}$ radius from stem and $15 \mathrm{~cm}$ deep using surface sterilized

172 sharpshooter shovels. This time point is referred to as "PRE-spray." Soil monoliths were placed

173 on a sieve and soil around the root ball was gently removed by shaking and passed through a 2

$174 \mathrm{~mm}$ sieve; this soil was considered bulk soil. Soil adhering to roots after this procedure

175 (considered rhizosphere soil) was brushed onto a $2 \mathrm{~mm}$ sieve using a camel hair brush. Roots

176 were brushed thoroughly, yet not so the integrity of the root surface was compromised. The

177 rhizosphere samples from the six plants were pooled and $5 \mathrm{~g}$ were added to a $15 \mathrm{ml}$ falcon tube 
containing $10 \mathrm{ml}$ of MoBio LifeGuard nucleic acid preservation solution. The contents of the tubes were mixed and frozen at $-80^{\circ} \mathrm{C}$. Plants were placed at $4{ }^{\circ} \mathrm{C}$ until processed further. Approximately twenty days after glyphosate was applied to the GR corn and soybean plots (at growth stage R2 to R3) the soil monolith sampling was repeated in the same plots. Samples were labeled "POST-spray." Roots and adhering soils were collected and processed the same as for PRE-spray samples. At each site, sampling was determined by the developmental stage of the crop plants and was not constrained by Julian calendar dates.

\section{Identification of Endophytes from Roots}

Two-centimeter sections of root were cut at random sixteen times from each of six fresh root systems for each treatment. The total wet weight of the 16 sections was recorded. Sections were surface sterilized for 2 minutes in $1.25 \%$ sodium hypochlorite, followed by three rinses in sterile distilled water. Sections were blotted dry on sterile paper towel and eight root sections were placed on a plate containing Komada's Medium [27]. Plated roots were incubated in ambient light at room temperature until colonies emerged. Fungal mycelium and spores from emerging colonies were sampled and examined on a Nikon E60 microscope and identified to genus, or to broader morphological group, based on taxonomic features. Colonies of typical morphology were plated onto minimal media to induce sporulation for further identification. Colonies not producing spores were characterized as "non-sporulating." Polymerase chain reaction (PCR) screens for ITS followed by cloning and sequencing were conducted on over 384 colonies of typical morphology to validate microscopic identification. The methods followed those described in (Chung et al. 2008). Sequences were quality checked and aligned using the DNAStar suite of software (DNAStar, Madison, WI, USA), and identified using the basic local alignment search tool and GenBank nucleotide data bank from the National Center for Biotechnology Information, Bethesda, MD, USA (http://www.ncbi.nlm.nih.gov/. Accessed fall, 2014).

\section{Illumina Sequencing Library Preparation from Rhizosphere Soils}


Rhizosphere and bulk soils preserved in LifeGuard at $-80{ }^{\circ} \mathrm{C}$ were thawed and $800 \mu \mathrm{l}$ of each slurry was processed using a PowerSoil-htp 96 Well Soil DNA Isolation Kit (MoBio Laboratories Inc, Solana Beach, CA) according to the manufacturer's recommendations. DNA was quantified and quality verified using a NanoDrop 2000 spectrophotometer (Thermo Fisher Scientific, Pittsburgh, PA). 16S metagenome sequencing was conducted according to the Illumina protocol Library Preparation Manual Part\# 1504423 Rev. B, Illumina Inc., www.illumina.com. Five $\mu \mathrm{l}$ of cleaned adapter amplicon product for each sample were used for

211 index PCR using the Nextera XT Index Kit (Part\# FC-131-1002; 16S Metagenomic Sequencing

212 Library Preparation Manual Part\# 1504423 Rev. B, Illumina Inc., www.illumina.com). Index PCR

213 products were cleaned according to the Illumina protocol (16S Metagenomic Sequencing

214 Library Preparation Manual Part\# 1504423 Rev. B, Illumina Inc., www.illumina.com), and $2 \mu$ l

215 aliquots per sample from each 96-well PCR plate were pooled for the final Illumina library. For analysis, one-hundred $\mu \mathrm{l}$ of $10 \mathrm{nM}$ solutions of each library pool were frozen and shipped on dry

217 ice for analysis on an Illumina MiSeq system at the Center for Genome Research and

218 Bioinformatics (CGRB), Oregon State University, Corvallis, OR. For the Beltsville site, where a 219 total of four cropping systems were also sampled, a total of 512 samples were sequenced. For 220 the Stoneville site 256 samples were sequenced.

\section{Bioinformatics and Statistical Analysis} control with standard Illumina workflows, including quality filtering and adapter trimming. Raw

224 data is available via the AgData commons NUMBER. Scripts used in subsequent steps can be 225 found at "https://github.com/rmkepler/FSP_script_repository". Prior to joining paired ends and 226 taxonomy assignment, forward and reverse primers were removed and sequences quality 227 trimmed (-q 22) at the 3-prime end using Cutadapt (version 1.8.3). Reads lacking primer 228 sequences or shorter than 75 bp before trimming were discarded. 
Assembly and taxonomy assignment. The R package Dada2 [28] was used for paired end assembly and taxonomy assignment. The command "filterandtrim" was used to remove sequences with an expected error rate greater than two, and any sequences containing "N" values (unreadable bases). Error rates were estimated for forward and reverse reads. Filtered

233 reads were then dereplicated with the "derepFastq" command. Dereplicated sequences were

234 denoised with the "dada" command and then paired ends were merged. Chimeric sequences

235 were removed with the command "removeBimeraDenovo". Taxonomy was assigned to the 236 chimera-free table of sequences with the dada2 implementation of the RDP classifier [29]. The

237 UNITE database (version 7.2) [30] was used as the reference for identification of fungal ITS

238 sequence variants, and silva (release 132) [31] was used for prokaryotes.

Community analysis. We transformed community count data into relative abundance,

240 then calculated Bray-Curtis dissimilarity. Principal components analysis (PCA) was applied to

241 the Bray-Curtis dissimilarity matrix using the ordinate function of the vegan package v. 2.4 [32]

242 as implemented in phyloseq v. 1.22.2 [33] for both fungal and prokaryotic barcodes.

After subsetting by crop and site, richness and evenness were estimated from rarefied

244 datasets of the raw sequence counts using vegan. DESeq2 v. 1.18 .1 [34] was used to produce

245 variance stabilized datasets [35]. Bray-Curtis dissimilarity for each sample was used for PCA.

246 We used PERMANOVA to determine significance of main effects and interactions between the

247 following factors: farming system, soil zone, glyphosate treatment, sampling date, and year. The

248 farming system factor had 4 categories for Beltsville (CT, NT, Org3 and Org6) and 2 for

249 Stoneville (NT_none, NT_15yr). All other factors had two categories at both sites: soil zone

250 (bulk and rhizosphere); year (2013, 2014); glyphosate treatment (spray, no spray); sampling

251 date (PRE glyphosate application, and POST glyphosate application). A repeated measures

252 model based on the plot ID was used.

253 The effect of glyphosate treatment on microbial communities was tested with the

254 Wilcoxon signed-rank test of differences between dates as implemented in the longitudinal plug- 
255 in for Qiime2 [36]. The test was applied separately for three measures of richness: observed,

256 Shannon's and Simpson's.

Differentially abundant taxa. Tests for differentially abundant taxa in response to glyphosate treatment were conducted in DESeq2 using likelihood ratio tests after subsetting fungal and prokaryotic data by site, crop, and farming system. The test compared a full model including group, sampling date terms, as well as an interaction term, where group is defined as the combination of farming system and glyphosate treatment (e.g. Org3_spray) and sampling date corresponds to PRE-spray and POST-spray sampling events. The full model was compared to a reduced model lacking the interaction term. Thus, significant interaction terms would indicate sampling date and glyphosate application interacted to be important predictors of microbial abundance. This was tested for every fungal and bacterial taxon identified. Datasets with untransformed counts were used as the starting data, which were then variance-stabilized during testing.

\section{Results}

From sequencing analysis a total of 68,964 unique fungal and 72,454 unique prokaryotic sequence variants were identified across all samples. Beltsville and Stoneville shared 13,964

271 bacterial and 5,740 fungal taxa. Stoneville featured 62,985 and 29,780 bacterial and fungal

272 taxa, respectively. Beltsville featured 41,538 and 44,924 unique bacterial and fungal taxa,

273 respectively. Fungal richness was higher for all Beltsville farming systems, compared with

274 Stoneville, with the exception of the Shannon's and Simpson's diversity metrics for Org_3

275 (Figure 1A). Conversely, prokaryotic diversity was greater for Stoneville in all measures (Figure 276 1B). 
0.16 ; supplemental data). Differences between the Stoneville and Beltsville microbial

communities were driven by differences in edaphic factors. Soil chemical characteristics differed between the two sites (Canonical Discrimination Analysis, $p<0.001, R^{2}=0.99$ ), and between cropping systems (Canonical Discrimination Analysis $p<0.001, R^{2}=0.99$ ). Soil in Stoneville was significantly higher in $\mathrm{pH}$ and the cations Arsenic (As), Barium (Ba) and Strontium (Anova, $p<0.001)$, whereas Beltsville soil contained significantly more Phosphorous $(P)$, Lead $(P b)$, Sulfur (S), Cromium (Cr), Iron (Fe) and OM (Anova, p<0.001) (Figure 1E). In order to increase power to detect local effects of glyphosate treatment, we analyzed sites and crop treatments separately.

Farming system was the largest driver of fungal community structure regardless of crop

(Figure $2 \& 3$ ) in both Beltsville (Permanova; corn: $p=0.001, R^{2}=0.16$; soybean; $p=0.001, R^{2}$

$=0.16$ ) and Stoneville (Permanova; corn: $p=0.001, R^{2}=0.24$; soybean; $p=0.001, R^{2}=0.23$ ).

Year of sampling was also significant but explained less variance in both Beltsville (corn: $p=$

$0.001, R^{2}=0.046$; soybean; $p=0.001, R^{2}=0.043$ ) and Stoneville (corn: $p=0.001, R^{2}=0.051$; soybean; $\left.p=0.001, R^{2}=0.052\right)$. No significant interaction was noted between sampling date and glyphosate treatment ( $p=0.488$ and 0.296 for corn and soybean, respectively).

Rhizosphere and bulk soil samples were also not significantly different (Supplemental data) for any crop or site. Likelihood ratio tests of taxon abundance in DESeq2 also confirmed no glyphosate treatment; the sampling date-glyphosate treatment interaction did not significantly increase the explanatory power of the model for any taxon (supplementary data), regardless of crop or farming system. (Permanova; corn: $p=0.001, R^{2}=0.096$; soybean; $p=0.001, R^{2}=0.09$ ) and Stoneville

304 (Permanova; corn: $p=0.001, R^{2}=0.21$; soybean; $p=0.001, R^{2}=0.16$ ). Farming explained less 305 variation in Beltsville prokaryotic communities (Figure 2), than in Stoneville (Figure 3). The year 306 term explained a lesser amount of variance for Beltsville (corn: $p=0.001, R^{2}=0.096$; soybean; 
$\left.p=0.001, R^{2}=0.086\right)$ and Stoneville (corn: $p=0.001, R^{2}=0.051$; soybean; $p=0.001, R^{2}=$ crop (Supplemental data). Likelihood ratio tests of taxon abundance in DESeq2 also confirmed no glyphosate treatment; the sampling date-glyphosate treatment interaction did not significantly increase the explanatory power of the model for any taxon (supplementary data), regardless of crop or farming system (supplementary data).

Wilcoxon rank sum tests showed several instances where species richness differed

314 significantly between the PRE and POST sampling dates (Figure 4, Supplemental Data);

315 however, differences were observed in both glyphosate and no-glyphosate treatments,

316 indicating this is a seasonality effect, and not due to glyphosate exposure. In Beltsville, corn and

317 soybean differed in their response over the two dates. Prokaryote richness for corn in every

318 Beltsville farming system was significantly different between the two dates. This trend was also

319 observed, but to a lesser degree in fungal communities, with half of the treatments differing

320 significantly for both spray and no spray treatments. Fungal communities did not differ seasonally in the Beltsville soybean plots, and fungal species richness was unaffected by sampling date for both corn and soybean in the Stoneville samples.

324 identified over 2400 fungal colonies. Significantly more colony forming units (CFU)s were 325 observed in 2013 than in 2014 at the Beltsville site $(p<0.0003)$, but no differences in the number 326 of CFUs were observed between years at the Stoneville site. A total of 384 of the typical 327 morphotypes were ITS amplicon sequenced, resulting in 11 identified dominant taxa: Fusarium $328 s p .$, Macrophomina sp., Alternaria sp., Cladosporium sp., Penicillium sp., Zygomycota sp., 329 Trichoderma sp., and Epicoccum sp. There was no significant difference in abundance of 330 Fusarium sp. or the other taxa in the glyphosate sprayed and unsprayed plots, regardless of 331 site, crop, or year ( $p>0.07)$ (Figure $4 b)$. 
There was no significant difference in corn yield among systems or among glyphosate application treatments for either 2013 or 2014 (Table 1). Corn yields were not significantly different from the county averages for all systems with a mean among systems of $9339.4 \mathrm{~kg} / \mathrm{ha}$. In 2013 an error occurred while using the small plot combine and beans harvested from different replicates were mixed, rendering the data unusable. In 2014 soybean yields were similar to the county averages with a mean of $2326.5 \mathrm{~kg} / \mathrm{ha}$. There was no significant difference in yield across farming systems, and no effect of glyphosate treatment on yield (Table 1)

\section{Discussion}

The structure of prokaryote and fungal communities among farming systems and between sampling dates were not driven by glyphosate use. Instead, tillage and carbon inputs appear to be the primary drivers of soil microbiome structure. For instance, even though the Beltsville site had a common history of no-till management prior to 1996, microbial communities today are easily differentiated by farming system. Differences in management have effects that extend beyond microbial taxa to include nematodes [37], as well as soil organic matter and

347 phosphorous concentrations, greenhouse gas emissions, and total energetic costs of the 348 farming system [24, 38, 39].

The absence of glyphosate effects in naïve soil communities suggests that typical application rates of glyphosate do not alter the overall microbial community. Existing literature suggests most microbial communities are susceptible to disturbance, although bias against

352 reporting of no treatment could affect this view [40]. Understanding the factors contributing to 353 resistance of microbes in agroecosystems remains an important goal [41]. In the current study

354 resilience to glyphosate spray could be linked to several factors. Some bacterial and fungal 355 species are known to metabolize glyphosate, and the presence of these organisms may protect 356 susceptible species $[42,43]$. Studies reporting effects of glyphosate on soil microbes often use 357 higher concentrations of the herbicide than the approved rate, which may overwhelm buffering 
by resistant members. Concentration-dependent effects of glyphosate on soil microbial respiration and biomass have been reported and are consistent with reports on other agrochemicals, showing only transient effects at recommended application rates [44].

Greenhouse studies with GR wheat conducted in the Pacific Northwest found only minor effects of glyphosate on microbial communities, and determined site was a major driver of soil microbial community structure $[20,21]$. While these studies did detect effects of glyphosate on the prevalence of a few microbial taxa, they applied glyphosate at twice the recommended rate, increasing the likelihood that the microbial community experienced a significant effect. These methodological differences may account for the detection of an effect on the abundance of some taxa after glyphosate exposure where none was detected here, and ultimately increase confidence in our finding that glyphosate has minimal effect on the microbial community when applied at the recommended rate.

The Beltsville and Stoneville sites differ in soil chemistry and physical characteristics

$371(\mathrm{OM}, \mathrm{pH})$. Soil microbial communities in these soils also differ considerably between sites

372 (Figure 1), with Beltsville having higher overall fungal richness and Stoneville having higher

373 prokaryotic richness (Figure 1). The higher richness of fungi and prokaryotes in Beltsville NT

374 plots relative to the other Beltsville management types receiving tillage is consistent with

375 previous studies, and may be due to the spatial heterogeneity that develops over time in the 376 absence of tillage [45]. However, in spite of differences in microbial communities between sites 377 and among management histories, fungal and prokaryotic richness were unaffected by 378 applications of glyphosate in all management and crop treatments. concentration (Figure 4). These results are similar to those of Hart et al. [46] in which the GR 381 corn and its genetically close isoline were grown for one season in Canada and the microbial 382 community compared by TRFLP with and without glyphosate application, although this study 383 could not have tested the long term legacy of glyphosate application. This study also found that 
seasonality was a significant controlling factor in microbial community structure with and without glyphosate under field conditions. Pseudomonas abundance decreased with glyphosate use [11]. In those studies, Fusarium were presumed to be pathogenic while Pseudomonas were presumed to be symbionts. However, our metabarcoding and culture data failed to detect an effect of glyphosate on the abundance of any Fusarium or Pseudomonas spp. And while both barcoding and culture surveys detected other pathogens, none responded to glyphosate (Supplementary Data). Our results are consistent with previous metabarcoding studies $[20,21]$.

It is important to note that the ITS and 16 s gene loci fail to resolve diversity at an adequate level to differentiate pathogenic genotypes from closely related non-pathogenic genotypes [47, 48]. For example, several species of Metarhizium known to occur at this site [49] were not represented in the samples from this study. Most likely pathogenic strains were not detected in this study. However, even if they are not identified to the strain level, pathogenic species contribute to the relative abundance of their constituent OTU, and we did not detect any change in total numbers of Fusarium spp. OTUs associating with crops due to glyphosate application. This holds true for other genera of pathogenic fungi such as Alterneria spp. and Macrophomina spp. (supplementary data). It should also be noted that while Pseudomonas spp. are often taken to be inherently beneficial, there are at least a few confirmed pathogens [48]; and the type of beneficial function may differ substantially across strains. Regardless, as with 404 fungi, no Pseudomonas spp. changed in prevalence as a result of glyphosate treatment. We also found no reductions in yield by glyphosate application on GR corn or GR 406 soybean in fields with a long history of glyphosate use or with no history of glyphosate use [50, 407 51]. In a similar study with GR sweet corn, there was even a slight increase in yield associated 408 with glyphosate application [52], which could have been due to hormesis, a phenomenon with 
non-phytotoxic doses of glyphosate [53]. Lack of effects on yields are consistent with no

410 substantial detrimental effects on rhizosphere microbes.

411 Although glyphosate is widely used across the globe, relatively few studies have

412 investigated the effect of this herbicide on soil microbial communities in cropping systems with

413 and without a legacy of glyphosate application. This work provides an important contribution into

414 determining the effect of glyphosate on bacterial and fungal communities found in soils. No

415 changes due to glyphosate, coupled with a trend towards higher species richness in no-till plots,

416 suggests this widely employed management practice is not at risk of altering soil microbial

417 communities in a negative manner. However, increased glyphosate application rates in

418 response to evolution of resistant weeds could alter this conclusion. Whether the species

419 richness of no-till systems translates to increases in ecosystem function supportive of crop

420 productivity remains to be fully elucidated.

\section{Acknowledgments}

422 Sarah Emche assisted with DNA extraction and sequencing preparation, root plating and isolate 423 identification. Other people helped and they are...

\section{Conflict of interest}

425 The authors declare they have no conflict of interest. 


\section{References}

429 1. Cohen JE. Human Population: The Next Half Century. Science 2003; 302: 1172-1175.

430 2. Tilman D, Balzer C, Hill J, Befort BL. Global food demand and the sustainable

431 intensification of agriculture. PNAS 2011; 108: 20260-20264.

432 3. Bruinsma J, Food and Agriculture Organization of the United Nations (eds). World

433 agriculture: towards 2015/2030: an FAO perspective. 2003. Earthscan Publications,

$434 \quad$ London.

435 4. Foley JA, DeFries R, Asner GP, Barford C, Bonan G, Carpenter SR, et al. Global

$436 \quad$ Consequences of Land Use. Science 2005; 309: 570-574.

437 5. Benbrook CM. Trends in glyphosate herbicide use in the United States and globally.

$438 \quad$ Environmental Sciences Europe 2016; 28: 3.

439 6. Steinrücken HC, Amrhein N. The herbicide glyphosate is a potent inhibitor of 5-

440 enolpyruvylshikimic acid-3-phosphate synthase. Biochemical and Biophysical Research

$441 \quad$ Communications 1980; 94: 1207-1212.

442 7. Johal GS, Rahe JE. Effect of soilborne plant-pathogenic fungi on the herbicidal action of 443 glyphosate on bean seedlings. Phytopathology (USA) 1984.

444 8. Johal GS, Huber DM. Glyphosate effects on diseases of plants. European Journal of $445 \quad$ Agronomy 2009; 31: 144-152.

446 9. Coupland D, Caseley JC. Presence of 14c Activity in Root Exudates and Guttation Fluid 447 from Agropyron repens Treated with 14c-Labelled Glyphosate. New Phytologist 1979; 83: $448 \quad 17-22$.

449 10. Torstensson L. Behaviour of glyphosate in soils and its degradation. In: Grossbard E, 450 Atkinson D (eds). The herbicide glyphosate / edited by E. Grossbard, D. Atkinson. 1985. $451 \quad$ Butterworths, London. 
11. Kremer RJ, Means NE. Glyphosate and glyphosate-resistant crop interactions with rhizosphere microorganisms. European Journal of Agronomy 2009; 31: 153-161.

12. Van Bruggen AHC, He MM, Shin K, Mai V, Jeong KC, Finckh MR, et al. Environmental and health effects of the herbicide glyphosate. Science of The Total Environment 2018; 616617: 255-268.

13. Hammerschmidt R. How glyphosate affects plant disease development: it is more than enhanced susceptibility. Pest Management Science 2018; 74: 1054-1063.

14. Martinez DA, Loening UE, Graham MC. Impacts of glyphosate-based herbicides on disease resistance and health of crops: a review. Environ Sci Eur 2018; 30: 2. Rhizoctonia and Fusarium root rot in sugar beet. Pest Management Science 2006; 62: 1182-1192.

16. Zobiole LHS, Kremer RJ, Oliveira RS, Constantin J. Glyphosate affects micro-organisms in rhizospheres of glyphosate-resistant soybeans. Journal of Applied Microbiology 2011; 110: 118-127.

17. Barnett KA, Sprague CL, Kirk WW, Hanson LE. Influence of Glyphosate on Rhizoctonia Crown and Root Rot (Rhizoctonia solani) in Glyphosate-Resistant Sugarbeet. Weed Science 2012; 60: 113-120.

18. Kandel YR, Bradley CA, Wise KA, Chilvers MI, Tenuta AU, Davis VM, et al. Effect of Glyphosate Application on Sudden Death Syndrome of Glyphosate-Resistant Soybean Under Field Conditions. Plant Disease 2014; 99: 347-354. 
20. Schlatter DC, Yin C, Burke I, Hulbert S, Paulitz T. Location, Root Proximity, and Glyphosate-Use History Modulate the Effects of Glyphosate on Fungal Community Networks of Wheat. Microb Ecol 2017; 1-18.

21. Schlatter DC, Yin C, Hulbert S, Burke I, Paulitz T. Impacts of Repeated Glyphosate Use on Wheat-Associated Bacteria Are Small and Depend on Glyphosate Use History. Appl Environ Microbiol 2017; 83: e01354-17.

22. Nguyen DB, Rose MT, Rose TJ, Morris SG, van Zwieten L. Impact of glyphosate on soil microbial biomass and respiration: A meta-analysis. Soil Biology and Biochemistry 2016; 92: $50-57$.

23. Cavigelli MA, Lengnick LL, Buyer JS, Fravel D, Handoo Z, McCarty G, et al. Landscape level variation in soil resources and microbial properties in a no-till corn field. Applied Soil Ecology 2005; 29.

24. Spargo JT, Cavigelli MA, Mirsky SB, Maul JE, Meisinger JJ. Mineralizable soil nitrogen and labile soil organic matter in diverse long-term cropping systems. Nutr Cycl Agroecosyst $2011 ; 90:$ 253-266.

25. Ross DS, Ketterings Q. Recommended methods for determining soil cation exchange capacity. Recommended soil testing procedures for the northeastern United States 1995; 2: $62-70$.

26. USEPA. Test Methods for Evaluating Solid Waste. Volume IA: 3rd Edition. EPA/SW-846. 1986. National Technical Information Service, Springfield, Va.

27. Komada H. Development of a selective medium for quantitative isolation of Fusarium oxysporum from natural soil. Review of Plant Protection Research 1975; 8: 114-124. resolution sample inference from Illumina amplicon data. Nat Meth 2016; 13: 581-583. 
500

501

502

503

504

505

506

507

508

509

510

511

512

513

514

515

516

29. Wang Q, Garrity GM, Tiedje JM, Cole JR. Naïve Bayesian Classifier for Rapid Assignment of rRNA Sequences into the New Bacterial Taxonomy. Appl Environ Microbiol 2007; 73: $5261-5267$.

30. Nilsson RH, Larsson K-H, Taylor AFS, Bengtsson-Palme J, Jeppesen TS, Schigel D, et al. The UNITE database for molecular identification of fungi: handling dark taxa and parallel taxonomic classifications. Nucleic Acids Res.

31. Quast C, Pruesse E, Yilmaz P, Gerken J, Schweer T, Yarza P, et al. The SILVA ribosomal RNA gene database project: improved data processing and web-based tools. Nucl Acids Res 2013; 41: D590-D596.

32. Dixon P. VEGAN, a package of R functions for community ecology. Journal of Vegetation Science 2003; 14: 927-930.

33. McMurdie PJ, Holmes S. phyloseq: An R Package for Reproducible Interactive Analysis and Graphics of Microbiome Census Data. PLOS ONE 2013; 8: e61217.

34. Love MI, Huber W, Anders S. Moderated estimation of fold change and dispersion for RNA-seq data with DESeq2. Genome Biology 2014; 15: 550.

35. McMurdie PJ, Holmes S. Waste Not, Want Not: Why Rarefying Microbiome Data Is Inadmissible. PLOS Computational Biology 2014; 10: e1003531.

36. Bokulich NA, Dillon MR, Zhang Y, Rideout JR, Bolyen E, Li H, et al. q2-longitudinal: Longitudinal and Paired-Sample Analyses of Microbiome Data. mSystems 2018; 3: e00219-18.

37. Treonis AM, Unangst SK, Kepler RM, Buyer JS, Cavigelli MA, Mirsky SB, et al. Characterization of soil nematode communities in three cropping systems through morphological and DNA metabarcoding approaches. Scientific Reports 2018; 8: 2004.

38. Cavigelli MA. Long-Term Agronomic Performance of Organic and Conventional Field Crops in the Mid-Atlantic Region. Agronomy Journal 2008; 100. 
39. Hoffman E, Cavigelli MA, Camargo G, Ryan M, Ackroyd VJ, Richard TL, et al. Energy use and greenhouse gas emissions in organic and conventional grain crop production: Accounting for nutrient inflows. Agricultural Systems 2018; 162: 89-96.

40. Shade A, Peter H, Allison SD, Baho D, Berga M, Buergmann H, et al. Fundamentals of Microbial Community Resistance and Resilience. Front Microbiol 2012; 3.

41. Busby PE, Soman C, Wagner MR, Friesen ML, Kremer J, Bennett A, et al. Research priorities for harnessing plant microbiomes in sustainable agriculture. PLOS Biology 2017; 15: e2001793.

42. Shinabarger DL, Braymer HD. Glyphosate catabolism by Pseudomonas sp. strain PG2982. Journal of Bacteriology 1986; 168: 702-707.

43. Dick RE, Quinn JP. Glyphosate-degrading isolates from environmental samples: occurrence and pathways of degradation. Appl Microbiol Biotechnol 1995; 43: 545-550.

44. Imfeld G, Vuilleumier S. Measuring the effects of pesticides on bacterial communities in soil: A critical review. European Journal of Soil Biology 2012; 49: 22-30.

45. Carson JK, Gonzalez-Quiñones V, Murphy DV, Hinz C, Shaw JA, Gleeson DB. Low Pore Connectivity Increases Bacterial Diversity in Soil. Appl Environ Microbiol 2010; 76: 39363942.

46. Hart MM, Powell JR, Gulden RH, Dunfield KE, Peter Pauls K, Swanton CJ, et al. Separating the effect of crop from herbicide on soil microbial communities in glyphosateresistant corn. Pedobiologia 2009; 52: 253-262.

47. Laurence MH, Summerell BA, Burgess LW, Liew ECY. Genealogical concordance

48. Curran B, Jonas D, Grundmann H, Pitt T, Dowson CG. Development of a Multilocus 
551 49. Kepler RM, Ugine TA, Maul JE, Cavigelli MA, Rehner SA. Community composition and 552 population genetics of insect pathogenic fungi in the genus Metarhizium from soils of a long-term agricultural research system. Environ Microbiol 2015; n/a-n/a.

554 50. Reddy KN, Cizdziel JV, Williams MM, Maul JE, Rimando AM, Duke SO. Glyphosate 555 Resistance Technology Has Minimal or No Effect on Maize Mineral Content and Yield. J Agric Food Chem 2018; 66: 10139-10146.

557 51. Duke SO, Rimando AM, Reddy KN, Cizdziel JV, Bellaloui N, Shaw DR, et al. Lack of 558 transgene and glyphosate effects on yield, and mineral and amino acid content of 559 glyphosate-resistant soybean. Pest Management Science 2018; 74: 1166-1173.

560 52. Williams MM, Bradley CA, Duke SO, Maul JE, Reddy KN. Goss's wilt incidence in sweet 561 corn is independent of transgenic traits and glyphosate. HortScience 2015; 50.

562 53. Brito IP, Tropaldi L, Carbonari CA, Velini ED. Hormetic effects of glyphosate on plants. Pest Management Science 2018; 74: 1064-1070. 
566 Figure 1. Principal component analyses of site chemistry, bacterial and fungal communities for

567 sites in Beltsville, MD and Stoneville, MS. A) Chemical analysis of all plots in the first year of this

568 study. B) Bray-Curtis dissimilarity of prokaryotic communities from all samples after rarefaction

569 to a depth of 20,000 reads per sample. C) Bray-Curtis dissimilarity of fungal communities for all

570 samples after relative abundance transformation of total counts.

572 Figure 2. Principal component analyses of microbial communities in Beltsville, MD, partitioned

573 by crop. Prokaryotic community data drawn from a dataset rarefied to 20,000 reads per sample.

574 Fungal data has been variance stabilized with negative binomial transformation in DESeq2.

576 Figure 3. Principal component analyses of microbial communities in Stoneville, MS, partitioned

577 by crop. Prokaryotic community data drawn from a dataset rarefied to 20,000 per sample.

578 Fungal data has been variance stabilized with negative binomial transformation in DESeq2.

580 Figure 4. Change in Shannon's richness of rarefied data across sampling dates in no-spray and 581 spray treatments. Stars on each plot are for raw $\left(^{*}\right)$ and false discovery rate corrected $\left(^{* *}\right) \mathrm{p}$ 582 values less than 0.05 from Wilcoxon signed-rank test of differences between dates. Years are 583 pooled, although graphed separately. Red points and line represent mean richness

585 Figure 5. Abundance of Fusarium isolates +/- standard deviation. A) corn. B) soy roots. Colors 586 follow those used in Figures $2 \& 3$. 
Corn yield at $15.5 \% \mathrm{H}_{2} \mathrm{O}(\mathrm{kg} / \mathrm{ha})$

2013

2014

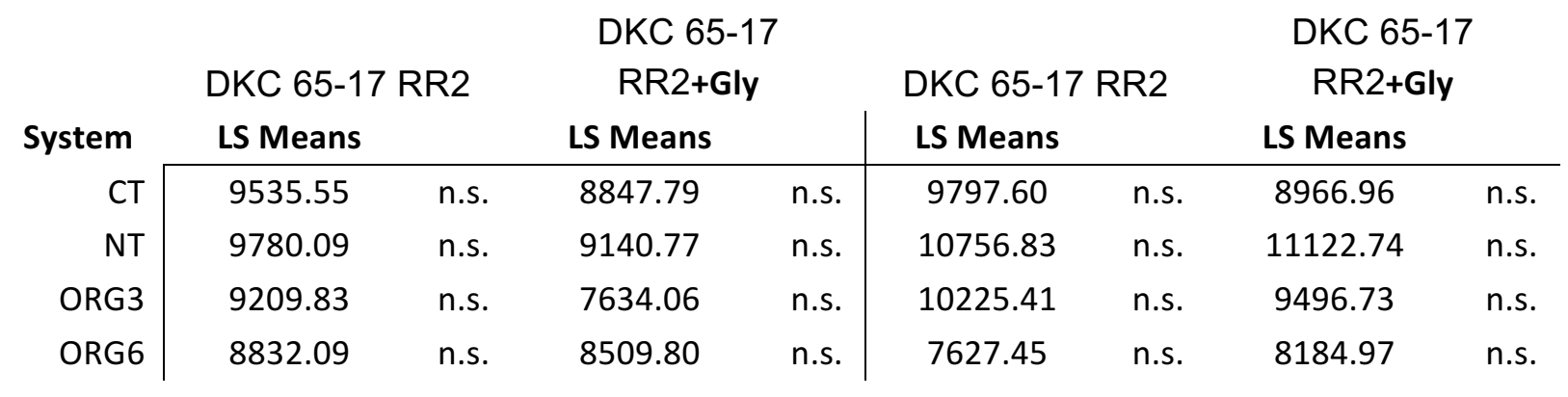

Soybean Yield at $13.5 \% \mathrm{H}_{2} \mathrm{O}(\mathrm{kg} / \mathrm{ha})$

2013

2014

\begin{tabular}{|c|c|c|c|c|c|c|}
\hline System & $\begin{array}{c}\text { Allen } \\
\text { LS Means }\end{array}$ & $\begin{array}{l}\text { Allen+Gly } \\
\text { LS Means }\end{array}$ & $\begin{array}{c}\text { Allen } \\
\text { LS Means }\end{array}$ & & $\begin{array}{l}\text { Allen+Gly } \\
\text { LS Means }\end{array}$ & \\
\hline $\mathrm{CT}$ & -- & -- & 2437.60 & n.s. & 2159.60 & n.s. \\
\hline NT & -- & -- & 2264.00 & n.s. & 2016.00 & n.s. \\
\hline ORG3 & -- & -- & 2314.50 & n.s. & 2906.50 & n.s. \\
\hline ORG6 & -- & -- & 2290.00 & n.s. & 2733.00 & n.s. \\
\hline
\end{tabular}

589 Table 1. Corn and Soybean yield (kg/ha) for glyphosate treated or untreated plots in chisel till 590 (CT), no-till (NT), Organic 3 yr. rotation (Org3) or Organic 6 yr. rotations (Org6). Comparison of 591 means was calculated within each system for the glyphosate resistant genotype either treated 592 with Glyphosate (Gly) or not. In 2013 an error in microplot harvesting resulted in mixing of 593 treated and untreated plots therefore making the yield data un-usable. 

A)
Fungi
B)
Prokaryotes
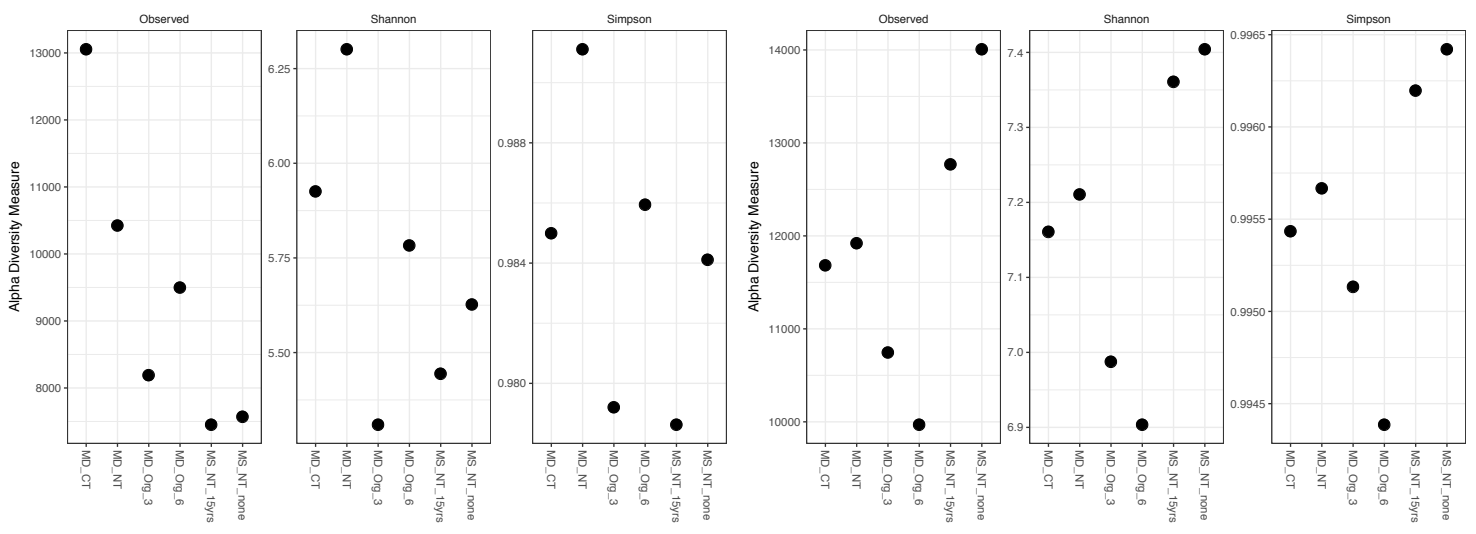

C)

D)

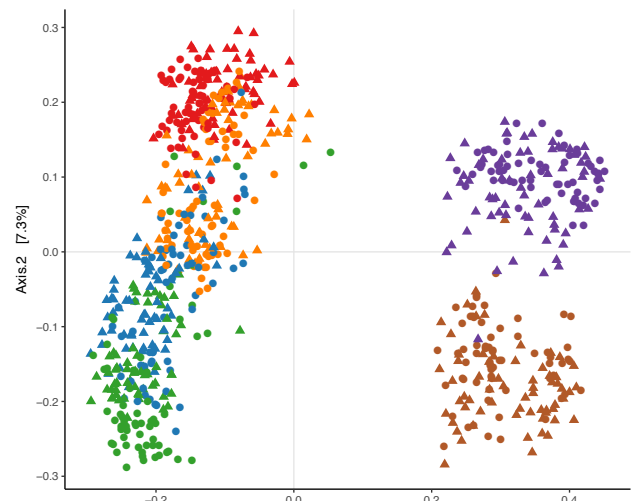

E)
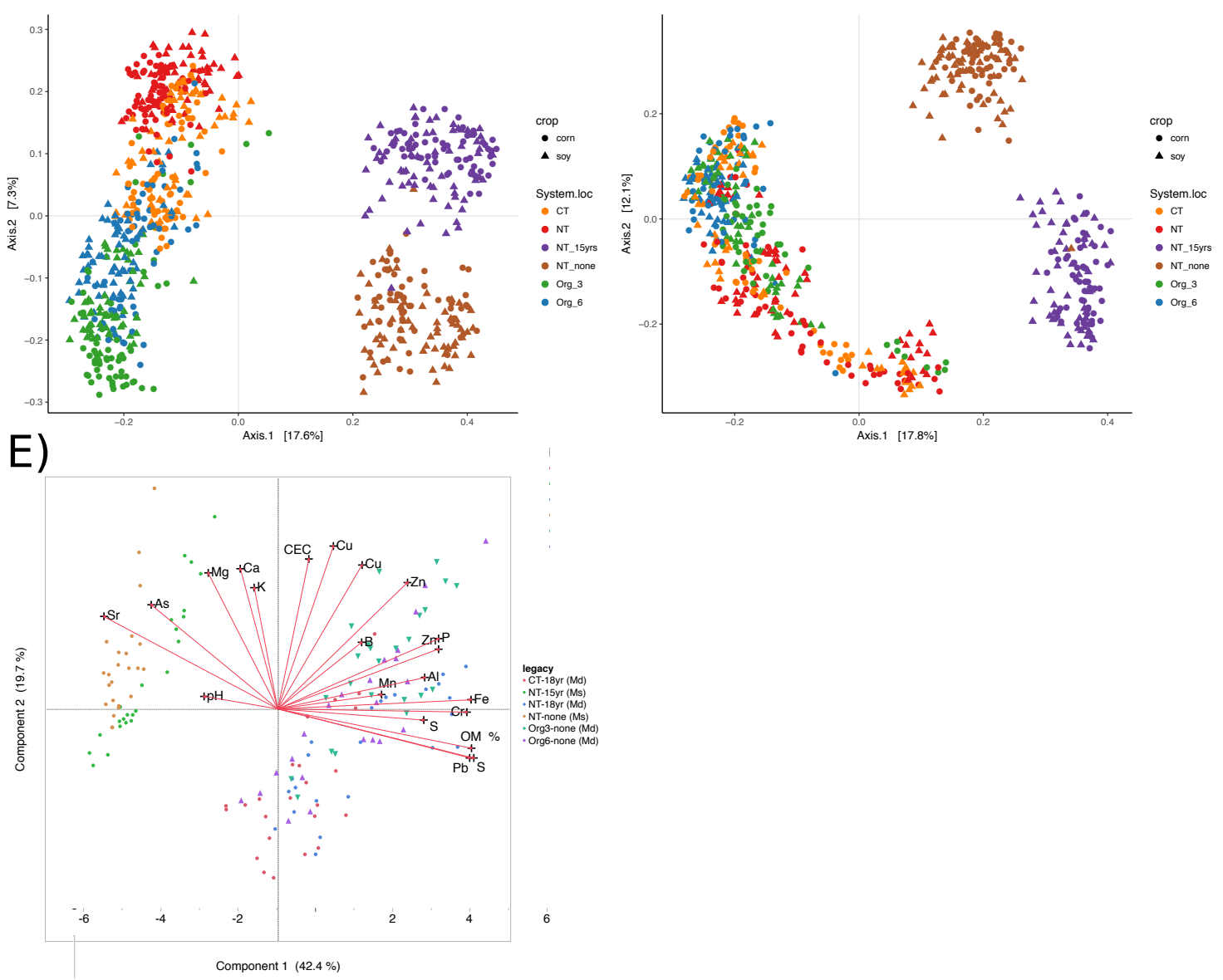
bioRxiv preprint doi: https://doi.org/10.1101/484055; this version posted December 6, 2018. The copyright holder for this preprint (which was not certified by peer review) is the author/funder. This article is a US Government work. It is not subject to copyright under 17 USC 105 and is also made available for use under a CCO license.

\section{Prokaryotes}

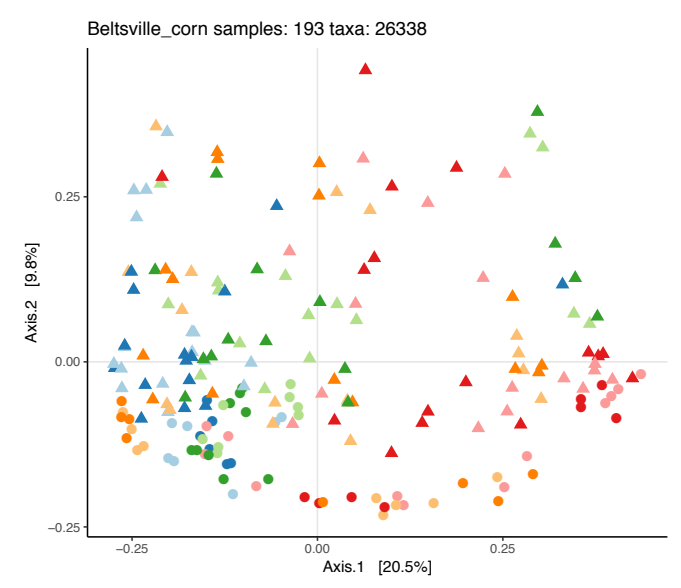

\section{Fungi}
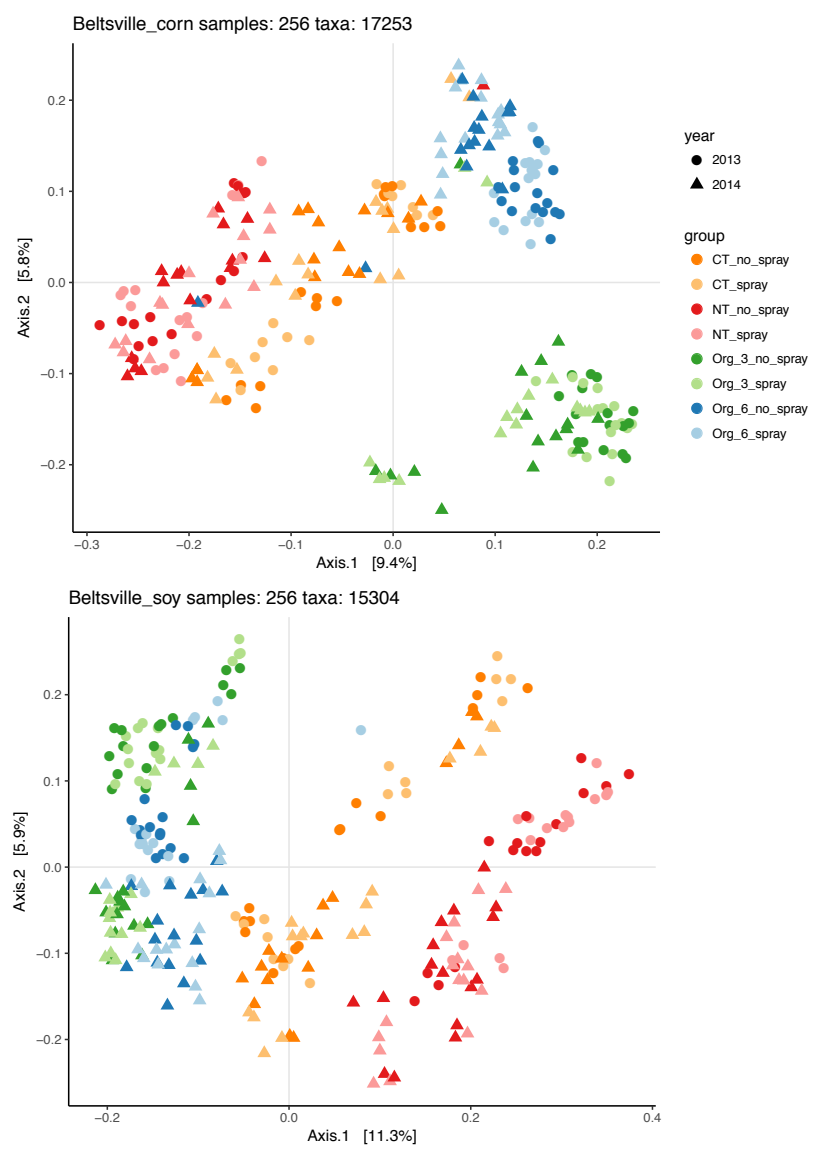

598 Figure 2 
bioRxiv preprint doi: https://doi.org/10.1101/484055; this version posted December 6, 2018. The copyright holder for this preprint (which was not certified by peer review) is the author/funder. This article is a US Government work. It is not subject to copyright under 17 USC 105 and is also made available for use under a CCO license.

\section{Bacteria}

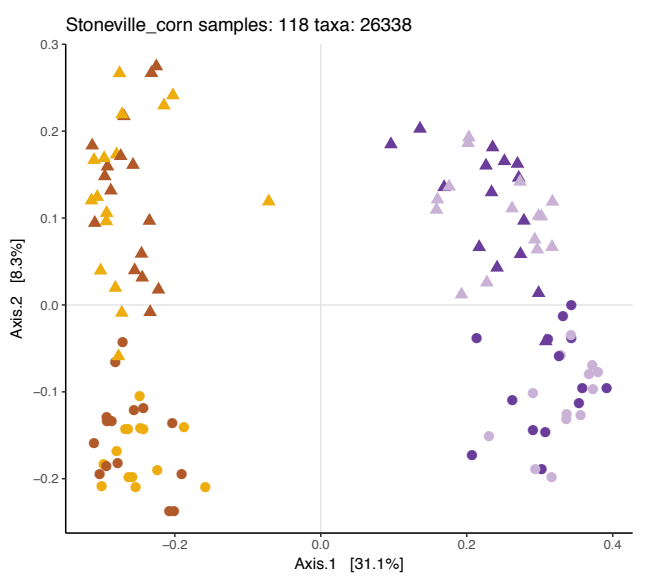

599

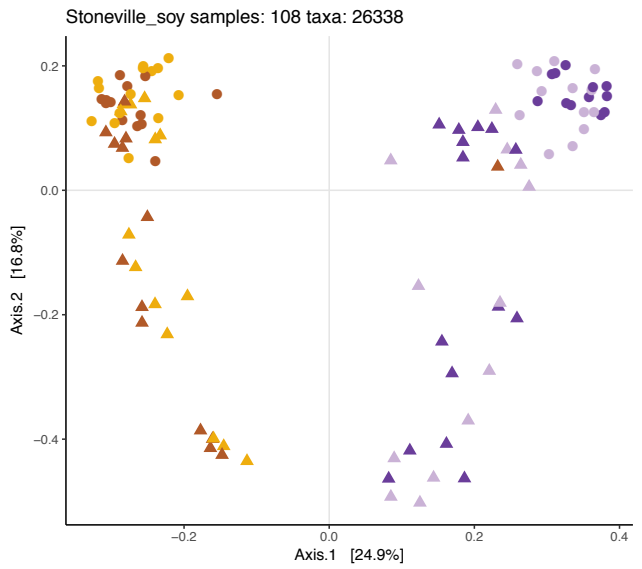

Fungi
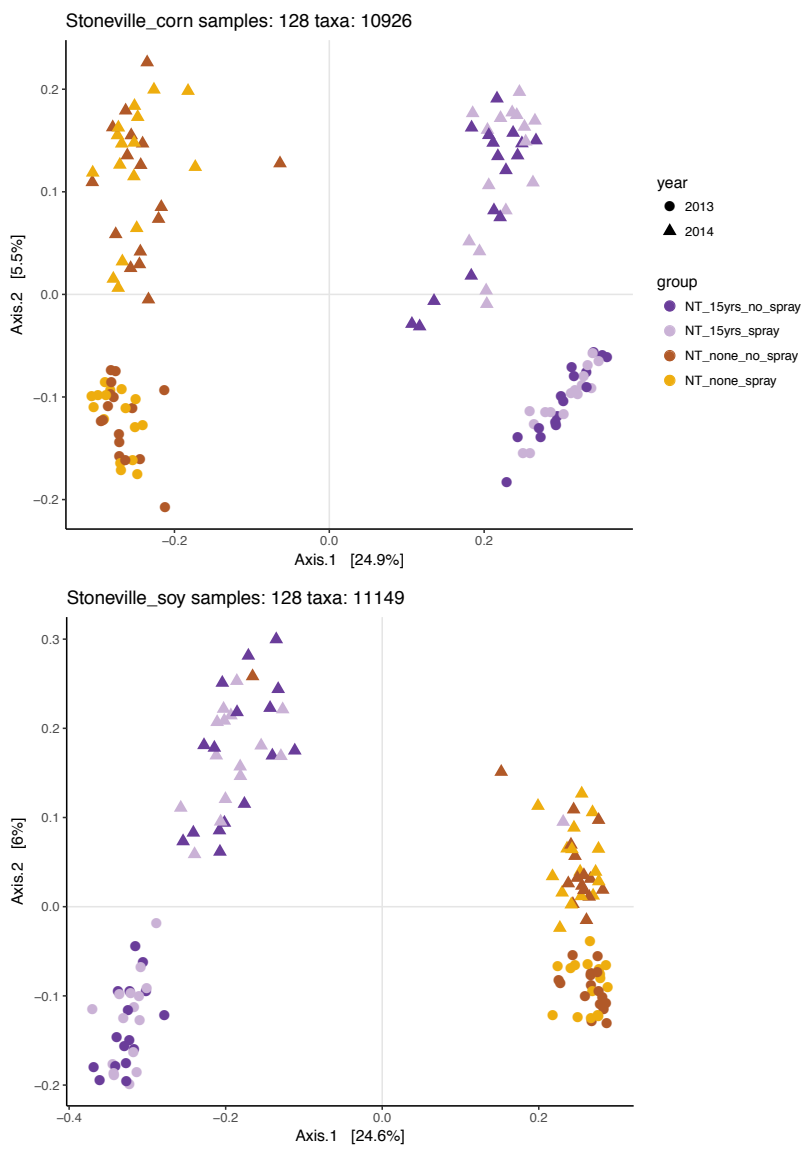

600 Figure 3 


\section{Bacteria}
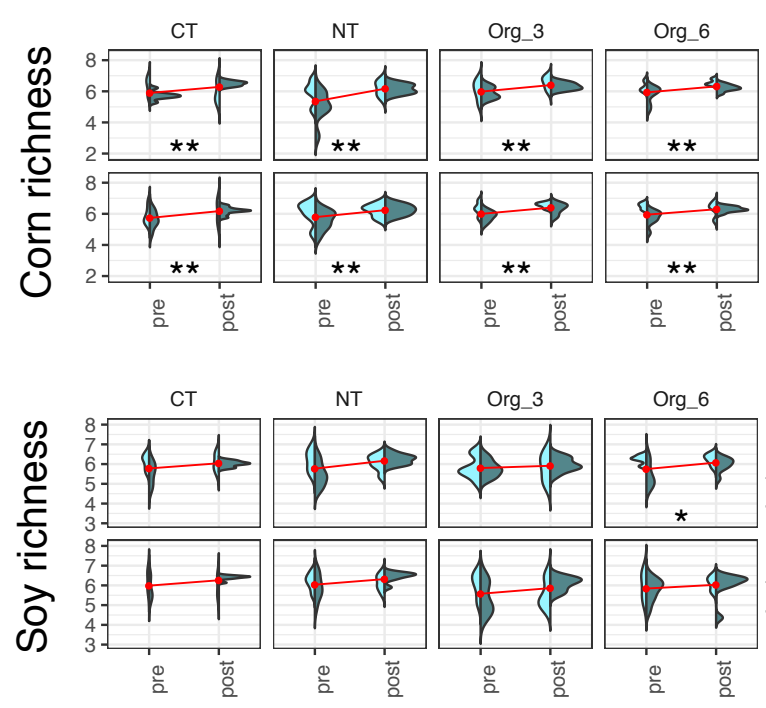

Org_3 Org_6

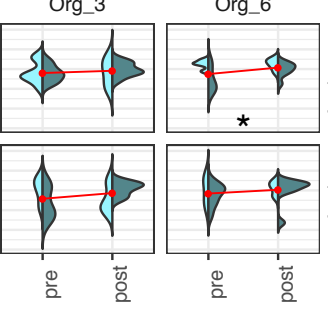

Fungi
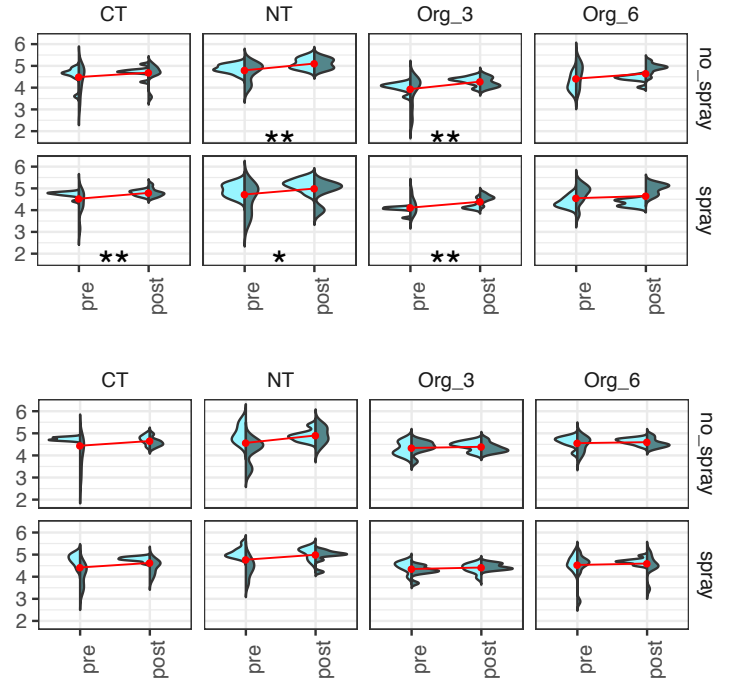

Sampling Date

year $\square 2013 \square 2014$

Figure 4 


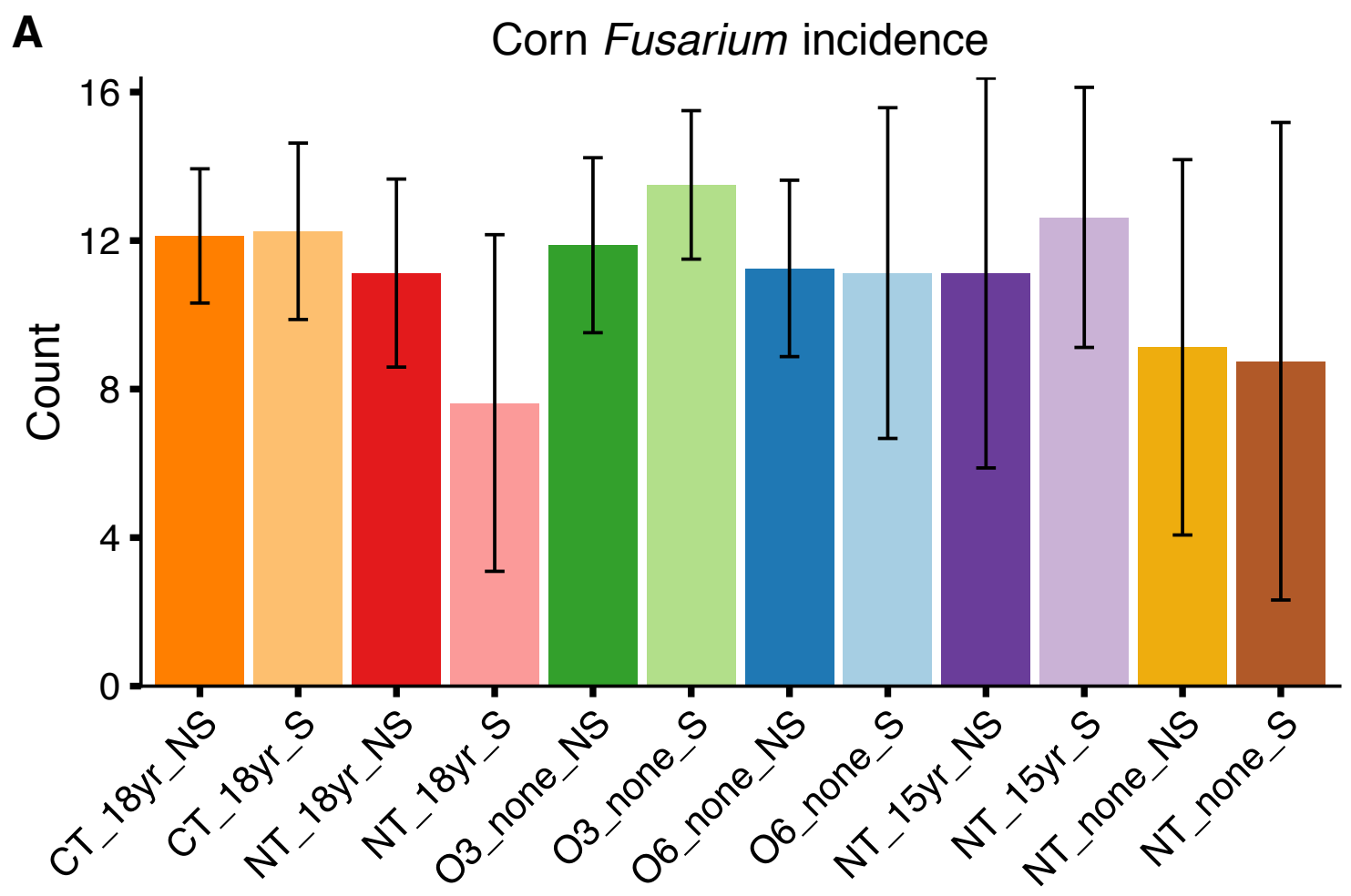

B

Soy Fusarium incidence

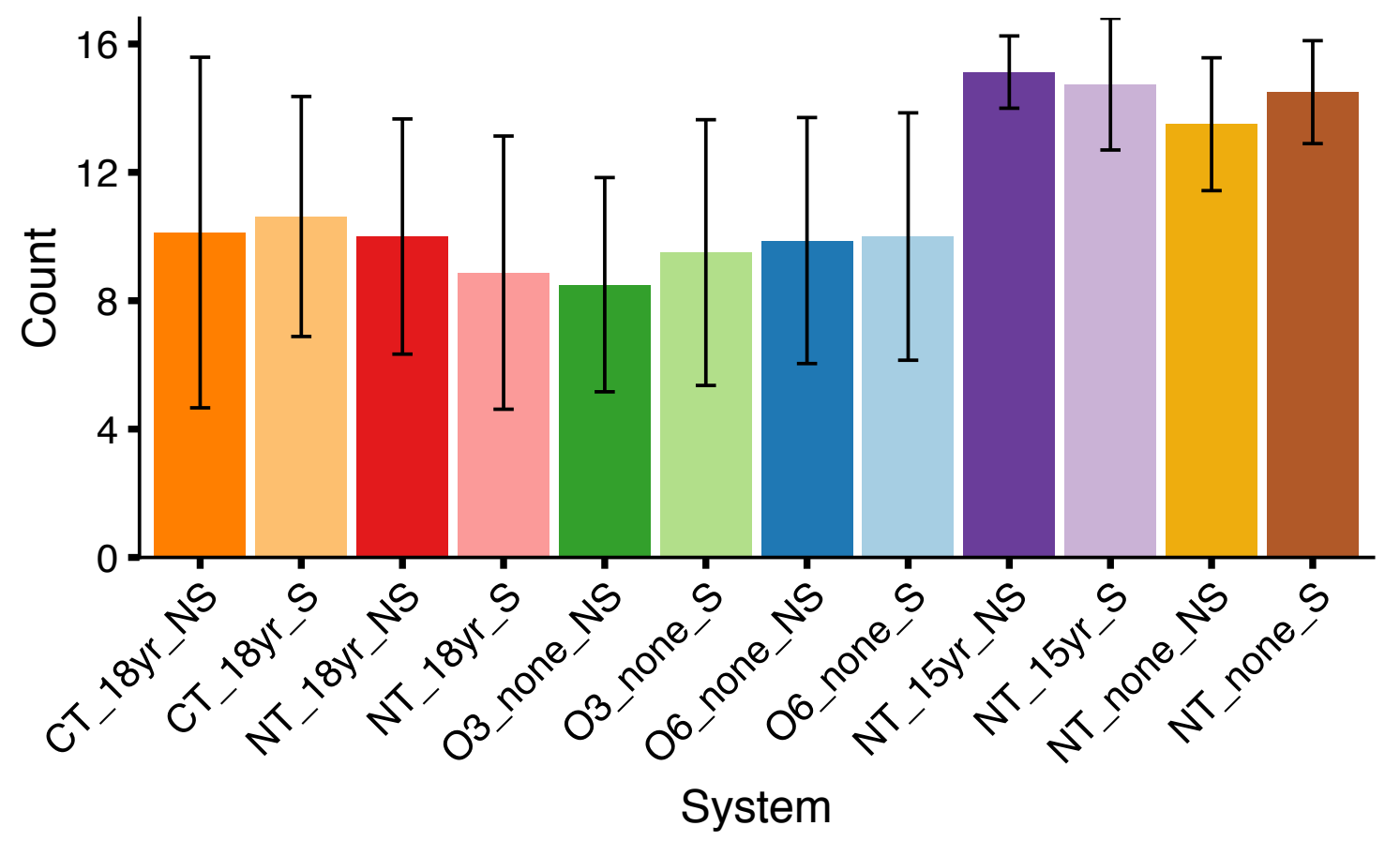

603

Figure 5 